\title{
Teen girl pregnancy pact?
}

\section{Susan Quilliam}

\section{Background}

Few recent stories about teen pregnancy have been so compelling as the item that surfaced in June 2008 in Time magazine, and was then zoomed around the world's media post haste.

The location is Gloucester, Massachusetts - America's oldest seaport. The venue is Gloucester High School. The protagonists are a 17-strong group of girls, aged 14-16 years, who over the past calendar year have become pregnant. The interest? First, this figure is much greater than the usual number (i.e. 4-10) of annual pregnancies at Gloucester High. Second, school principal Joseph Sullivan is quoted as saying that several of the pregnancies were due to a 'pact' between the girls. Cue media frenzy.

\section{Blame and backlash}

Cue also wholesale condemnation of the 'pact' and blame for its occurrence; for a few days the press is full of outrage. Then, cue wholesale backlash from Gloucester, as Mayor Carolyn Kirk moves into action by stating that Sullivan was confused, after which the good citizens of Gloucester understandably close ranks. Two months later, as I write this article, the story is more or less dead, its demise hastened by a media blackout in Gloucester on the community consultancy that is trying first to explore and then resolve the problem.

This leaves us with very little but hypotheses to try and make sense of what happened. But the very fact that we are left with so little is of interest in itself, because this closing of ranks demonstrates that the story has struck a huge and painful chord in Gloucester Massachusetts, while the media coverage demonstrates that it has done the same in the world at large.

\section{"Midwich Cuckoos"}

For it seems that the idea of 17 teenage girls 'agreeing' to get pregnant together fills society with terror. Don't get me wrong. I'm not suggesting that the pregnancies were a good idea, or that we as professionals shouldn't be doing our best to lower the teen pregnancy rate. But had these 15-yearolds all agreed to go to the same college, or all agreed to take the same job, we would not have been so afraid. And had they agreed to get pregnant at the same time but been in their early-30s, we would have lauded them for clever family planning. Instead, early coverage spoke of "bringing babies into the world on a dare"; early rebuttals denied a "blood-oath bond". Horror story stuff indeed.

No, it seems to me that it is precocious sexual and parental autonomy that is scaring us here: the fact that girls of 14 years of age are taking their lives into their own hands. When faced with such seemingly premature group decision-making we feel threatened, out of control. Shades of The Midwich Cuckoos, Village of the Damned and the malevolent power of the adolescent informers in the Salem Witch Trials (which, of course, actually happened only 10 miles from Gloucester.)

J Fam Plann Reprod Health Care 2008; 34(4): 265-266

\section{Cambridge, UK}

Susan Quilliam, BA, Cert Ed, MNLP, Freelance Writer, Broadcaster and Agony Aunt

Correspondence to: Ms Susan Quilliam.

E-mail: susan@susanquilliam.com

\section{Was there a pact?}

Did the girls make a communal decision to get pregnant and raise their children together? Gloucester's official spokespeople deny it. All of the pregnant girls who agreed to be identifiably quoted deny it. All of the fathers who were interviewed deny it. The general consensus among the media now is that it was unlikely. The professionals on the scene, however, have from the start backed the pact theory. As early as last autumn, Sue Todd, the chief executive of the day care centre, reported that her social workers had heard of the girls' plan to get pregnant. In March, the school clinic's medical director and his assistant were so worried about the high number of pregnancy tests - and the refusal of the clinic to sanction contraceptive prescriptions - that they resigned.

\section{The idea of 17 teenage girls 'agreeing' to get pregnant together fills society with terror.}

In the same month, a local newspaper quoted both the school principal and superintendent as saying the pregnancies were intentional, and the former as saying that girls presenting for pregnancy tests were leaving 'crestfallen' if those tests proved negative. Plus, although most of the media reports focused on the girls who denied a pact, some of the journalists spoke to girls who refused to be quoted and came away with the impression that there was some sort of agreement, probably among the younger and less well-educated girls. To cite the London Times journalist Stefanie Marsh, who visited the town in the wake of the media frenzy: "my own view ... is that there was a (minority) knot of girls who made a pact".

\section{Possible motivations}

It seems likely, then, that there may have been an agreement. The next question, then, is surely why? Why would girls make a communal decision to get pregnant; and what do lessons do their reasons hold for the wider world of family planning?

To begin with, I turn to the initial response to the Gloucester story, which contained a flurry of interpretations from various interest groups. High on the blame list was the issue of whether teens have enough - or too much - information and knowledge. Mayor Carolyn Kirk was quoted as blaming the recent US government diversion of funding from sex education meaning that such education is now only offered to students up to the age of 15 years. (Abstinence campaigners, on the other hand, equally cited State Governors' blocking of abstinence programmes in schools.)

Also high on the blame list was lack of contraceptive provision; as mentioned before, the inability of staff at Gloucester High to prescribe contraception was such that key members of staff resigned. It has also been claimed that the strongly Catholic population of Gloucester opposed any contraceptive advice at all. In order to get confidential provision students had to go across the river to another clinic and staff from that clinic were quoted as saying that "people were afraid their cars would be recognised if they parked outside". 
Education and provision are - as numerous studies have pointed out - absolutely crucial to teenage pregnancy rates. On this occasion, however, I beg to differ. Both factors are, if not irrelevant, certainly less than central to the crucial question at to why Gloucester's teenagers chose to get pregnant. They didn't get pregnant because they didn't know how to protect themselves against it; they got pregnant because they wanted to. They didn't fail to use contraception; they opted not to use it.

\section{Probable motivations}

So what did underpin this situation? Research has consistently shown a link between teen pregnancy and lack of community and family resources, and Gloucester officials themselves point the finger in this direction. A struggling economy in the area, they claim, is not only leaving parents working two jobs and so unable to give their teens proper support, but also leaving teenagers facing a life of unemployment; in this context, the motherhood career path may seem a perfect option.

\section{Research has consistently shown a link between teen pregnancy and lack of community and family resources.}

Which leads us to another issue, namely that teens can see parenthood as 'perfect' because they have no idea of its demands and responsibilities. In the nuclear family of today, siblings are grouped, and families conduct their business behind closed doors, so few teenage girls see the $24 / 7$ rearing of newborns and toddlers. They never get to see the 'joys' of night feeds and temper tantrums; the nearest they get to baby care is handing round a delightful cousin and then handing him or her back once the howling starts.

There is very little media coverage of the demands of parenthood, though there is an abundance of media coverage of the joys of sexuality.

Plus, in the media, there is currently a great deal of propregnancy coverage - both of celebrities getting pregnant, and of films that eulogise pregnancy. In the aftermath of Gloucester, the finger was pointed particularly at the recent film, Juno, in which a teenage girl goes through a seemingly trouble-free pregnancy, hands her baby over to the ideal adoptive mother and then resumes her previous life without a hitch. There is very little media coverage of the demands of parenthood, though there is an abundance of media coverage of the joys of sexuality.

\section{Longing for love}

But trumping even these issues surely for teenagers is the issue of self-esteem. Having a baby confers huge status; at a life stage when adolescents are most lacking in self-belief and self-esteem this can be irresistible. As we all do, teens want to both be loved and to love, unconditionally, and a baby can represent an instant package of such acceptance. Becoming a mother also gives a fast track to adulthood, at a time when adolescents want such an identity. Plus, of course, there is the factor of peer support. If one is a teenager - and thus highly influenced by peer pressure then if one's friends not only approve of one's pregnancy choice, not only make the same choice, but are also willing to swap reciprocal support once the choice becomes reality, then the way ahead must seem absolutely clear. And particularly if, as a teenage girl, one's same-gender peers are the only ones you can rely on. Parents and teachers don't understand. Potential partners have walked away. At least you can rely on your mates. Perhaps, just perhaps, that is what the Gloucester girls thought.

The best of sex education and the best of contraceptive provision will only help those teenagers who don't want to get pregnant.

\section{Not a horror story}

The bottom line is that we aren't going to find out what happened at Gloucester until the dust has cleared, and that may not be for decades. My suggestion is this: that the best of sex education and the best of contraceptive provision will only help those teenagers who don't want to get pregnant. If they are making a positive choice, with positive - if inaccurate and unwise - motivation, then nothing on earth will stop them making babies. What we saw at Gloucester wasn't a horror story. It wasn't utter irresponsibility, rampant sexuality or inherent wickedness. It was almost certainly a deep and powerful desire for love and acceptance. It's that which, if anything, is the moral of this twenty-first century tale.

\section{Statements on funding and competing interests}

Funding None identified.

Competing interests None identified.

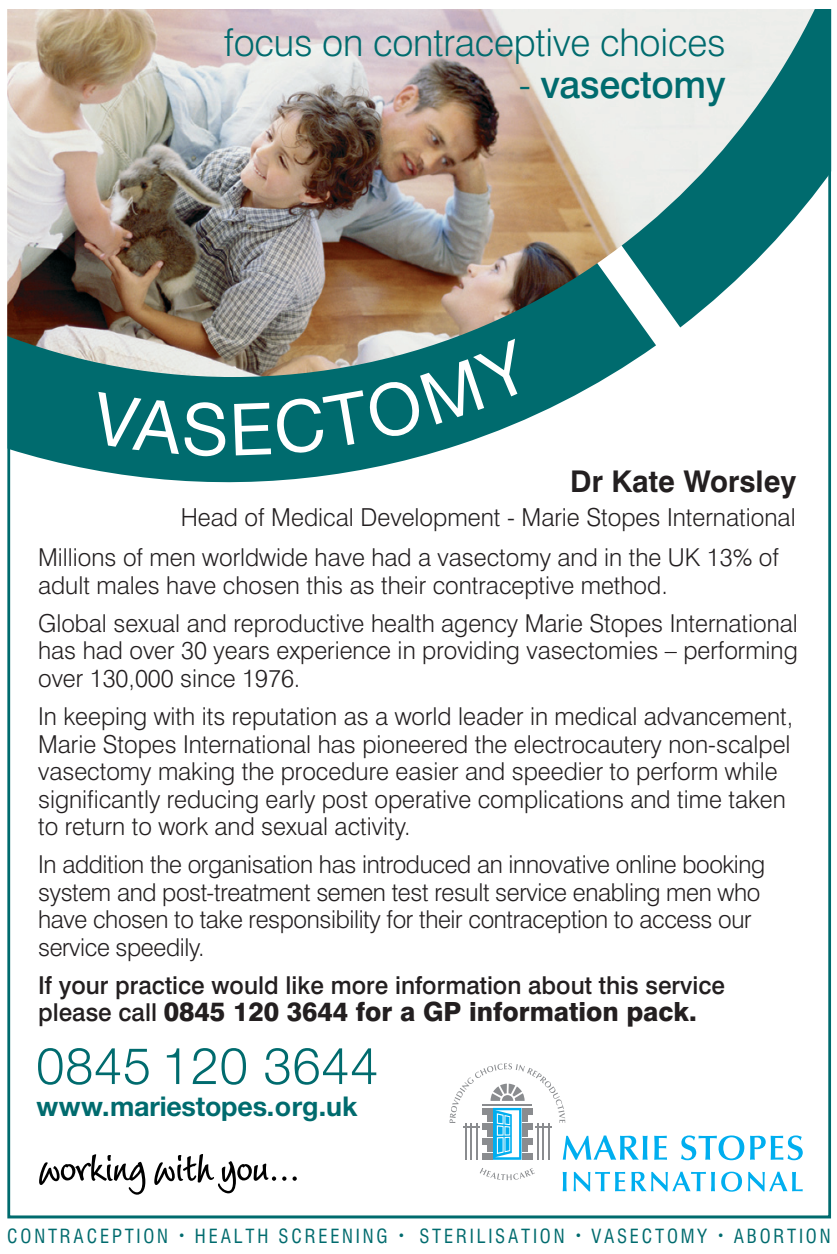

